and Tübingen, where biomedical research is particularly strong.

Biomedical scientists in Germany perceive a separate crisis increasing legislative restrictions that make it more difficult to carry out animal experiments. Hearing little to the contrary from researchers themselves, the public tends to assume that animal experiments are an unnecessary evil, so politicians respond with more restrictions.

That problem was a major motivation for the Basel Declaration drafted and signed at a meeting in Basel, Switzerland, last week (see page 742). Its signatories pledge to engage in open debate with the public about their work on animal experiments, to stress the high ethical standards to which they adhere and to explain why they have to do it. They intend, for example, to visit local schools or to mention that their research used animals when speaking to the press about new results. Germany does not have a national organization such as Understanding Animal Research to manage and maintain this public outreach. Now is the time that it should.

During the UK crisis, Understanding Animal Research used the momentum of the campaign against extremist violence to engage British scientists to establish a public dialogue. Education on the medical value of animal research helped to dismantle knee-jerk public sympathy for animal-rights campaigns and encouraged politicians to act.

In the 1990s, the pharmaceutical industry largely abandoned Germany as a research base, put off by restrictions on genetic technologies and the use of animals. Today the country is a leader in biomedical research, and red tape around genetic technologies has been significantly reduced. Yet the animal issue remains sensitive. Scientists there have tended to keep their heads down and hope for the best. But they should fear the worst: a crisis such as that in Britain could arise at any time. Some of the five main German

research organizations, such as the Max Planck Society, which runs 80 research institutes in different disciplines, and the DFG, Germany's main research-granting agency, acknowledge the animalexperiment problem and have small offices that monitor legislative activities. But they do not engage in significant public outreach.

The solution must be a single, non-partisan national office that can implement the principles of the Basel Decla-

The animal

issue has an intrinsically emotive nature and is never going to go away. as the formidable Alliance of German Science Organizations - the 'Allianz'. Successive governments have deferred to it, and have committed to long-term funding increases even in times of financial crisis.

The Allianz is the appropriate body to create and fund a German organization analogous to Understanding Animal Research. Including industry might breed distrust. The Basel Declaration has shown that animal researchers in Germany are willing to go public. A small investment by all members of the Allianz would bolster this new solidarity and serve as insurance for Germany's biomedical effort and for the new biomedical industries that are springing up.

The animal issue has an intrinsically emotive nature and is never going to go away. To keep the public ignorant of the benefits of animal research - without which it is currently impossible to develop any new therapies - was never a solution.

\section{Give up the ghosts}

Funding agencies should make researchers reveal industry links.

$\mathrm{T}$ The spectral fingerprints of a big drug company have once again been found all over academic publications. Documents released last week by a watchdog group based in Washington DC raise concerns about the role of writers paid by GlaxoSmithKline (GSK) in works attributed to psychiatric researchers at a number of US institutions. They add to the drumbeat of allegations in recent years indicating that such ghostwriting - in which articles contain substantial portions written by someone who is not listed as an author - is endemic in the biomedical literature.

The documents were made available as a result of litigation over GSK's antidepressant Paxil (paroxetine) and were pounced on by the Project on Government Oversight, which raised concerns about authorship of a research article, journal editorial and textbook.

The researchers did acknowledge the alleged ghostwriters of the textbook and the editorial in notes, but only for "editorial support". For the journal article, which appeared in a supplement to Psychopharmacology Bulletin, GSK is thanked for an "unrestricted educational grant". But the original front page of the manuscript - which the academic author is instructed to remove before submission to the journal - declares that it was prepared by writers from Scientific Therapeutics Information, a company based in Springfield, New Jersey, hired by GSK. The article and textbook discuss the uses of Paxil. The editorial, in Biological Psychiatry, gives an overview of depression as a major and growing public-health problem - which certainly does no harm to a company aggressively marketing an antidepressant.

The academic authors and the American Psychiatric Association, which published the textbook, have strongly denied that the pharmaceutical giant influenced its content. So, too, have the authors of the editorial and the journal article. GSK shareholders, then, may wonder what the company got for its money. The issue here is not that industry-financed experts cannot write useful and unbiased reports, but that their role must be declared in full. It is for readers, not authors, to conclude that there is no conflict of interest.

All the academic authors involved in this case have been recipients of US National Institutes of Health (NIH) funding; all but one still are. The NIH may argue, rightly, that the ghostwritten publications did not use its money. It will also note, correctly, that this in an issue that demands far broader action. Both are beside the point. Money is fungible, and rarely do the studies and intellectual output of senior researchers divide neatly into industry-funded and taxpayer-funded work. If its grantees are not playing by the rules, the NIH is tarred and public trust is damaged. So, how clear are the rules on ghostwriting? A study last year found that just 10 out of 50 top US academic medical centres had explicit, web-accessible policies that prohibit the practice. Another three banned ghostwriting in practice without naming it as such (J. R. Lacasse and J. Leo PLoS Med. 7, e1000230; 2010).

Discussing the issue of ghostwriting a year ago, Francis Collins, the NIH director, said publicly that he was "shocked" that "people would allow their names to be used on articles they did not write, that were written for them, particularly by companies that have something to gain by the way the data is presented". Many will share that shock, but, unlike Collins, few are in a position to do something about it. The agency is "considering how best to address and ensure" greater transparency and accountability as its grantees develop and author articles, Sally Rockey, NIH chief of extramural research, told Nature in an e-mail last week.

A good start would be for the NIH to require all institutions that $\rightarrow$ NATURE.COM To comment online, click on Editorials at: go.nature.com/xhunqv take its funds to articulate, publicize and vigorously enforce a clear ban on ghostwriting. Other funders should follow suit. Without such a clear signal, and the willingness to give a ban teeth, this troubling ghost will linger at the feast. 